\title{
Empowering women and addressing marital violence through self-help groups: Evidence from rural Bihar-Policy brief
}

\author{
K.G. Santhya \\ Population Council
}

Shireen J. Jejeebhoy

Follow this and additional works at: https://knowledgecommons.popcouncil.org/departments_sbsr-pgy

Part of the Demography, Population, and Ecology Commons, Domestic and Intimate Partner Violence Commons, Family, Life Course, and Society Commons, and the International Public Health Commons How does access to this work benefit you? Let us know!

\section{Recommended Citation}

Santhya, K.G. and Shireen J. Jejeebhoy. 2017. "Empowering women and addressing marital violence through self-help groups: Evidence from rural Bihar," Policy brief. New Delhi: Population Council. 


\section{Introduction}

Wide and deeply entrenched gender disparities in terms of power, resources, and attitudes about male entitlement and female submissiveness persist in India. Intimate partner violence is an extreme manifestation of these gender disparities and affects millions of women in India, violating their rights, while at the same time affecting their health and ability to exercise agency in their life. In recognition of the need to reverse gender disparities, India has instituted numerous policies, laws, and programmes intended to empower women and to protect women from violence. However, evidence on what works and what does not work to change notions of masculinity and femininity, reverse the widespread acceptability of marital violence at community level, and reduce women's experience of intimate partner violence remains limited in the country.

The Do Kadam Barabari Ki Ore (Two Steps Towards Equality) project sought to fill this gap in evidence. It was implemented among married women who were members of self-help groups (SHGs) and their husbands. The Population Council together with partners, the Centre for Catalyzing Change (C3) and the London School of Hygiene and Tropical Medicine, with support from UKaid, implemented the project in one district (Nawada) of Bihar, using the platform of self-help groups that are supported by the Women Development Corporation, Government of Bihar. Self-help groups are an appropriate platform because their goal is to empower women and because their format-fortnightly meetings with emphasis on both financial and social issues-offered an ideal setting for the activities of the programme. This brief describes the intervention and presents the effect of exposure to it in transforming attitudes relating to gender roles, reducing marital violence experience, and enhancing agency, financial literacy, and access to social support among SHG members.

\section{Do Kadam Barabari Ki Ore}

The intervention comprised gender transformative group learning sessions delivered fortnightly to SHG members and delivered monthly to husbands of SHG members, together with interactive voice response system (IVRS) messages delivered to husbands through their phones. The gender transformative group learning curriculum for SHG members focused on empowering them economically as well as exposing them to topics relating to gender discrimination, notions of masculinity, and the acceptability of violence against women and girls; the curriculum for husbands focused more exclusively on issues related to notions of masculinity and violence against women. Sessions for SHG members were delivered by Sakhi Salahkars or peer mentors drawn from the SHG, who underwent pre-programme and regular refresher training programmes, together with facilitators, known as field animators, from the implementing agency C3 India. Sessions for husbands were delivered by C3 India's field animators in view of husbands' irregular attendance and their unwillingness to take on the role of peer mentors. The project also sought to link SHG members with livelihood training opportunities and access to credit.

The intervention also supported SHG members and their husbands to reach other married women and men from the community through community-wide activities. A range of community events were conducted, including street plays and meetings, followed by discussions about their messages.

To evaluate the effects of exposure to the programme, we used a cluster randomised trial (CRT) design, with 14 villages each in two intervention arms (one in which we focused on SHG members only and a second one in which we focused on SHG members and their husbands) and one control arm (in which no intervention activities were implemented). We interviewed a total of 1,686 currently married women in ages 18-49 who were members of the SHGs and 688 husbands of SHG members ${ }^{1}$ before we launched the intervention in 2013. Of these, 96 percent of SHG members and 80 percent of their husbands were successfully re-interviewed following the conclusion of intervention activities. Additionally, we held in-depth interviews with selected SHG members and husbands of SHG members who had participated in the baseline survey from the intervention villages at three points in time-before launching the intervention (baseline), about 6-7 months into the intervention (midline), and after the intervention was over (endline); 20 SHG members and 10

\section{POPULATION} COUNCIL

Ideas. Evidence. Impact.

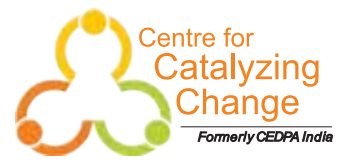

LONDON SCHOOL of HYGIENE \&TROPICAL MEDICINE

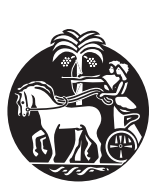


husbands were interviewed at baseline, of whom 19 SHG members and five husbands responded in all three interviews.

As seen in figure 1, at baseline, large proportions of SHG members held traditional gender role attitudes and notions of masculinity, including notions that a man has the right to control his wife and that it is a woman's duty to be subservient to her husband. Substantial proportions of women had experienced emotional violence, physical violence, and sexual violence perpetrated by their husband (figure 2).

Figure 1: Attitudes relating to gender roles among SHG members in intervention and non-intervention villages, baseline survey, 2013

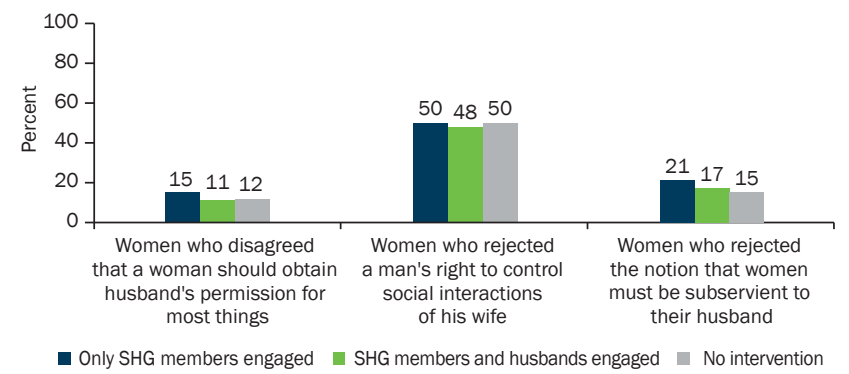

Figure 2: Marital violence experience in the six months prior to the interview reported by SHG members in intervention and non-intervention villages, baseline survey, 2013

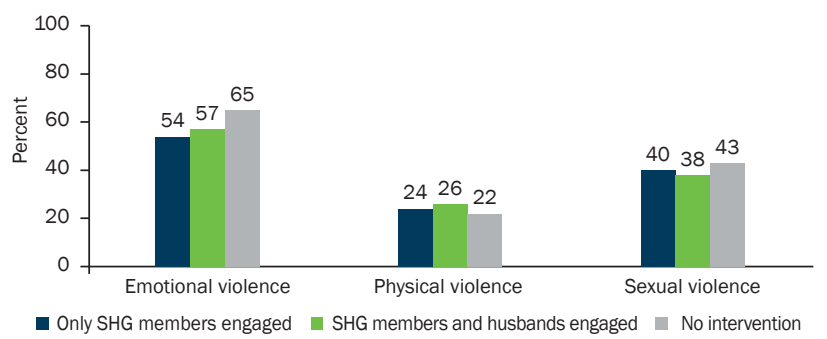

\section{Participation in Do Kadam Barabari Ki Ore programme}

Participation of SHG members and their husbands in project activities varied. Over 90 percent of SHG members and 67 percent of husbands of SHG members had attended at least one gender transformative group learning session (figure 3). Fewer-65-73 percent of SHG members and 28 percent of husbands-had attended regularly, that is, half or more sessions. Of the SHG members who had attended at least one gender transformative group learning session, the majority (61-74 percent) could recall all the themes that had been discussed in the sessions, and 43-52 percent had learned something new. Among husbands, 41 percent could recall all the themes and 21 percent had learned something new. One-fifth of husbands had also received at least one message via IVRS. Some 23-30 percent of SHG members and 20 percent of husbands had participated in organising a community/social mobilisation activity around the issue of violence against women and girls (VAWG) and alcohol abuse, while many more had attended such events (figure 4).
Figure 3: Participation of SHG members and their husbands in transformative group learning sessions, intervention villages, endline survey, 2015

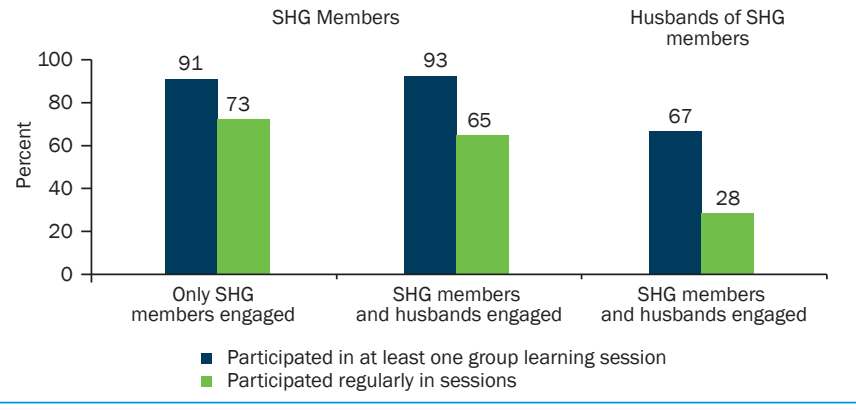

Figure 4: Participation of SHG members and their husbands in community/social mobilisation activities, intervention villages, endline survey, 2015

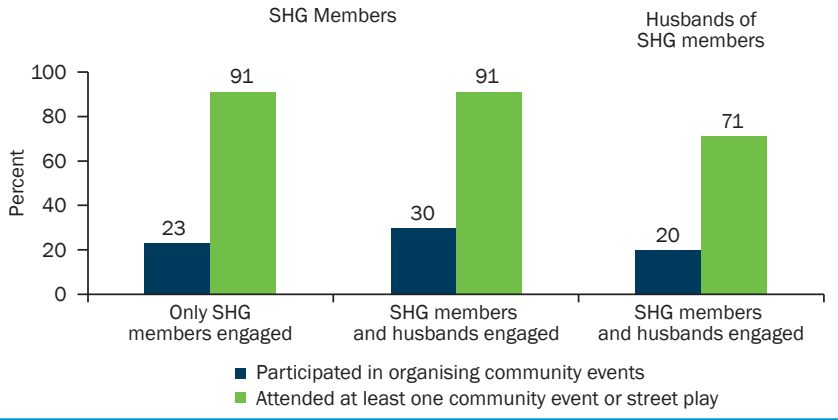

How did exposure to the Do Kadam Barabari Ki Ore programme influence attitudes and experiences of SHG members?

We compared outcome measures among SHG members in the intervention arm in which we targeted only SHG members with those among members of the control arm. Findings show that participation in the Do Kadam programme had a mixed effect on changing attitudes and experiences of SHG members.

More SHG members upheld egalitarian gender role attitudes, including those within marital relationships

At the conclusion of the programme, a significantly larger proportion of SHG members in intervention than control arms expressed egalitarian gender role attitudes and rejected the notion that men had the right to exercise control over their wife. They agreed, for example, that a woman need not obtain her husbands' permission in most situations, that a man should not tell his wife with whom she can or cannot socialise, and that a woman need not be subservient to her husband (figure 5). Changes in gender role attitudes, as reflected in the responses of a study participant in the course of her baseline and endline interviews, respectively, are given below.

Baseline: No they are not equal. For example, if a woman says anything to her husband, he doesn't need to do it, but the woman has to do whatever her husband says. A man can push the animal cart [plough] for farming but the woman can't, so how are they equal? The work of a man 
and a woman are different. How can they be equal? Can a woman do what a man can? Can a woman push the plough for farming? No she cannot.

Endline: Yes they are equal. I have to listen to what he says and he has to listen to what I say, so aren't we equal? When I joined the group and interacted with the people of the group, this change came about in my thinking. [SHG member, age 35, completed Class 5]

Figure 5: Gender role attitudes reported by SHG members in villages in which only SHG members were engaged and villages in which no intervention activities were implemented, endline survey, 2015

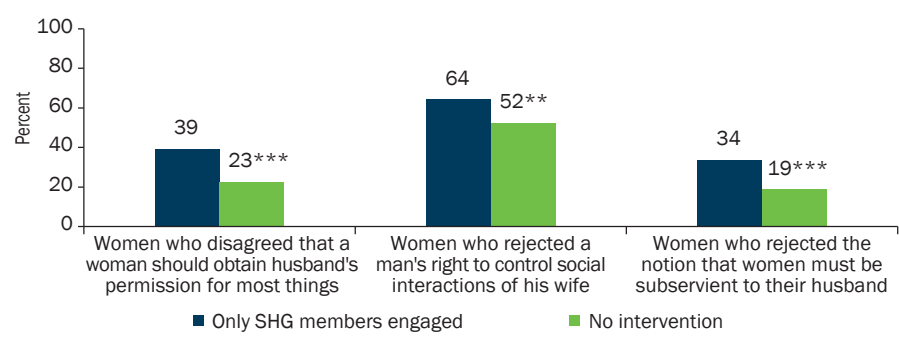

Note: **and $* * *$ indicate that difference between intervention and control arms was significant at $p<=0.01$ and $p<=0.001$, respectively.

\section{Effect on experience of marital violence varied}

Compared with women in the control arm, SHG members in the intervention arm reported significantly higher levels of emotional violence perpetrated by their husband in the six months preceding the interview, which suggests that perhaps participation in the programme encouraged women to defend themselves and thereby attract greater emotional abuse in the short run than those who continued to silently accept the abuse (figure 6). In contrast, they reported significantly lower levels of physical violence perpetrated by their husband in the six months preceding the interview than did those from the control arm; however, this effect weakened once associations were adjusted for covariates. Finally, exposure to the intervention had no effect on SHG members' experience of sexual violence in the six months preceding the interview.

Figure 6: Marital violence experience in the six months prior to the interview reported by SHG members in villages in which only SHG members were engaged and villages in which no intervention activities were implemented, endline survey, 2015

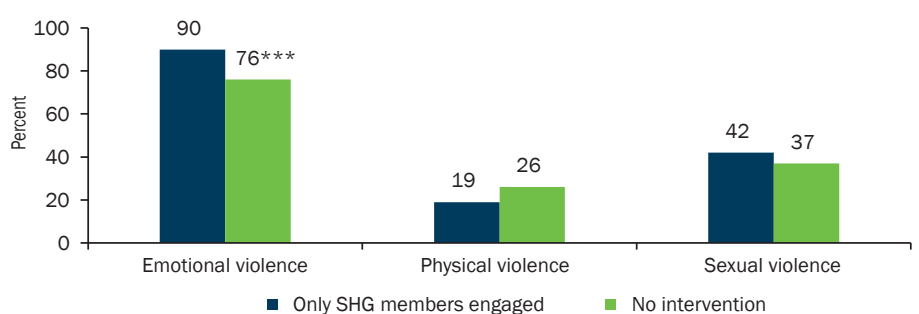

Note: $* \star *$ indicates that difference between intervention and control arms was significant at $p<=0.001$ respectively.

\section{Agency, financial literacy, and access to social support among SHG members increased}

Exposure to the intervention had a significant effect in empowering SHG members. SHG members in the intervention arm, for example, were more likely than those in the control arm to report decision-making authority and control over economic resources (figure 7). They were also more likely to display financial literacy. Likewise, exposure to the intervention strengthened women's access to peer networks and social support in case of trouble, even when covariates were adjusted.

Figure 7: Agency, financial literacy, and access to social support reported by SHG members in villages in which only SHG members were engaged and villages in which no intervention activities were implemented, endline survey, 2015

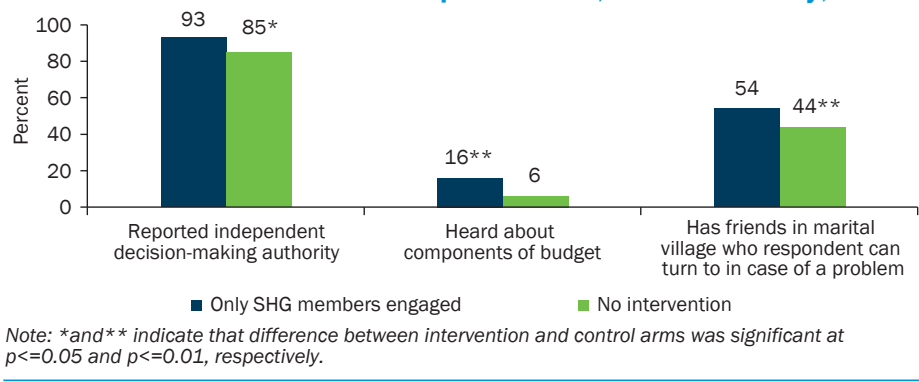

Did targeting SHG members and their husbands lead to a stronger effect than targeting only SHG members?

We found no support for our hypothesis that engaging husbands as well as SHG members will have a stronger effect on changing attitudes and experiences among SHG members than intervening only with SHG members. We acknowledge that the challenges faced in engaging husbands regularly were perhaps the underlying cause of these disappointing findings, and that, as such, we were unable to effectively test whether engaging husbands does indeed have a supplementary effect on outcomes for SHG members (figure 8 and 9).

Figure 8: Gender role attitudes reported by SHG members in villages in which only SHG members were engaged and villages in which SHG members and husbands were engaged, endline survey, 2015

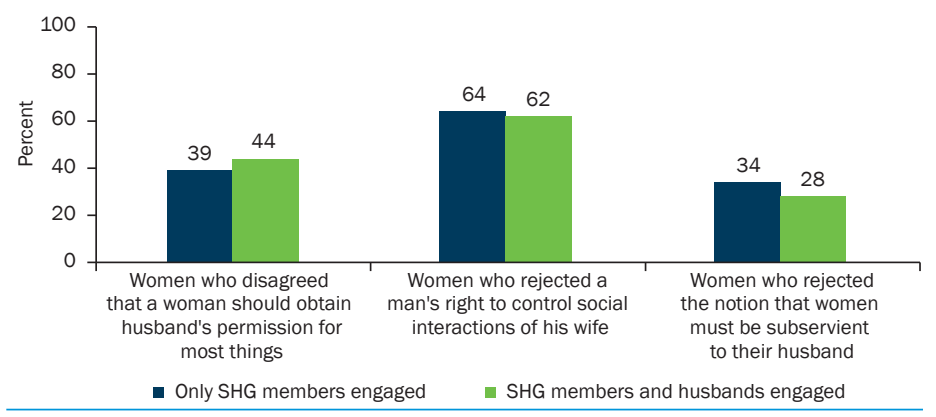

Figure 9: Marital violence experience in the six months prior to the interview reported by SHG members in villages in which only SHG members were engaged and villages in which SHG members and husbands were engaged, endline survey, 2015

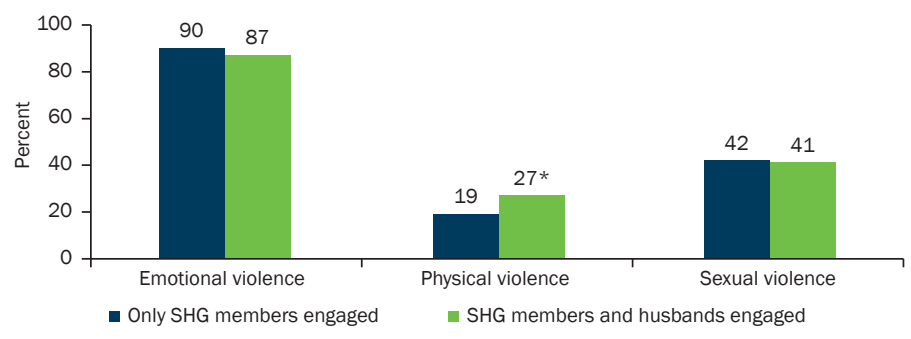

Note: ${ }^{\star}$ indicates that difference between intervention and control arms was significant at $p<=0.05$. 


\section{Programme recommendations}

The Do Kadam programme was acceptable and effective in many ways. Its gender transformative group learning curriculum was effectively transacted and tested, its quality commended by study participants, and its effect in improving SHG members' agency, financial literacy, and access to social support and changing their gender role attitudes observed. The programme holds considerable promise for replication and upscaling, with some modification, and can easily be incorporated within the SHG structure at state level. Recommendations arising from our experience in implementing the programme are detailed below.

- Our experience shows that not all SHGs meet fortnightly or discuss social issues such as child marriage and women's rights as is expected of them. In order for the Do Kadam programme to be effectively replicated and embedded in the SHG structure, SHG systems must be strengthened, meetings held regularly, and the capacity of members to effectively control their accounts enhanced.

- Many SHG members are poorly educated; numeracy and literacy are limited, and there is a lack of confidence and skills in public speaking and in organising and leading meetings and other public events among SHG leaders. It is important that programmes recognise these challenges and include a literacy and numeracy skills component, and, at the same time, provide repeated capacity-building measures and continuous supportive supervision to SHG members, particularly for those in leadership positions, in order to build their facilitation skills and their ability to empower other members of their SHG and community. Further, strong efforts are needed to empower women economically. Programme designs are needed that accommodate SHG members' own preferences for livelihood training and income-generating opportunities and that enable them to open, operate, and control bank accounts.

- Our intervention failed to engage husbands. Clearly, while men must be reached, we need to consider different platforms for reaching husbands, for example, through pre-existing forums-farmers' groups, men employed in a particular industry, or men belonging to different mandals and clubs-and through those holding authority and playing leadership roles at village level.

- Efforts to engage SHG members and their husbands as agents of change within their wider communities also proved challenging, and the reach and effect of the events conducted by SHG members and their husbands were modest at best. Sustained efforts to develop SHG members' agency and confidence in organising public events, speaking publicly, collectivising, and intervening in incidents of violence and alcohol abuse may be effective in enabling SHG members to mobilise communities and make communities more responsive to their messages.

\section{Acknowledgements}

The authors would like to gratefully acknowledge insightful comments that Thoai Ngo, Mamta Kohli and Nel Druce made on earlier versions of this brief; Komal Saxena helped in the design and production of this brief. The authors also gratefully acknowledge the financial support provided by the UK Department for International Development (DFID).

This brief has been developed based on the following publication: Jejeebhoy, S.J., K. G. Santhya, Rajib Acharya et al. 2017. Empowering women and addressing violence against them through self-help groups (SHGs). New Delhi: Population Council.

Suggested citation: Santhya, K. G and S. J. Jejeebhoy. 2017. Empowering women and addressing marital violence through self-help groups: Evidence from rural Bihar, Policy Brief. New Delhi: Population Council.

\section{Population Council}

Population Council

Zone 5A, Ground Floor

India Habitat Centre, Lodhi Road

New Delhi, India 110003

Phone: +91-11-2464 2901

Email: info.india@popcouncil.org

The study has been funded by UK aid from the UK Government; however the views expressed do not necessarily reflect the UK Government's official policies.
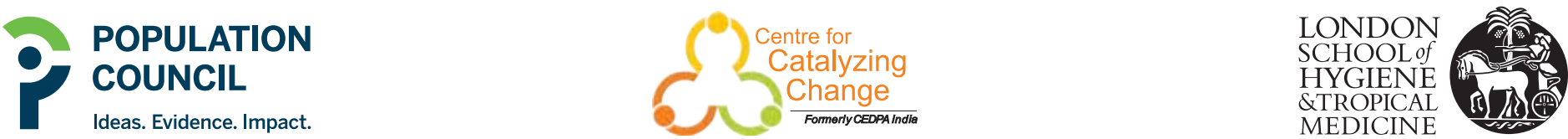

The Population Council conducts research and delivers solutions that improve lives around the world. Big ideas supported by evidence; it's our model for global change.www. popcouncil.org

(c) 2017 The Population Council, Inc. 